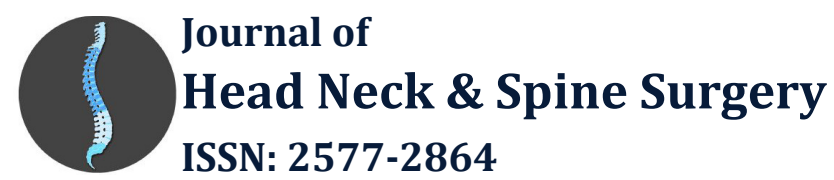

\title{
Simulation in ENT- Is There a Place For It?
}

\author{
Dione $\mathrm{L}^{*}$ \\ East Surrey Hospital, UK \\ Submission: March 10, 2017; Published: April 25, 2017 \\ *Corresponding author: Dione L, East Surrey Hospital, UK, Email: dione.lother@gmail.com
}

\section{Introduction}

Airway emergencies are a common presentation in the emergency department, with the incidence reported to range between $2 \%$ and $14.8 \%$ Kovacs et al. [1]. In the vast majority of cases, 'difficult airway' presentations are managed successfully by emergency medicine doctors Wong et al. [2]. While anaesthetic staff on the whole manage the remainder, surgical doctors (especially those working within ENT surgery) are often involved in cases that require invasive interventions such as tracheostomy or surgical cricothyroidotomy Awad et al. [3]. Furthermore, it is often the most junior member of the ENT team is first to attend to those patients requiring emergency on-call airway services; frequently without immediate senior supervision or support.

Despite this, there is currently no formal curriculum in airway management for core surgical trainees (ISCP, 2013) and as such, training is highly variable. Awad et al. [3] conducted a survey assessing competence of emergency airway management amongst one hundred ENT surgical house officers in the United Kingdom and reported that only 54\% of respondents felt their training in this area was adequate and felt confident to provide emergency airway services. Furthermore, the authors found that attendance at ALS or ATLS courses correlated poorly with trainee confidence and perceived adequacy of training.

While there is a large availability of airway management courses, the majority appear to be aimed at the anaesthetic audience. Of those available to alternative groups, most are either too basic or too advanced to meet the requirements of the core surgical trainee working in ENT [4].

\section{Rationale for simulation}

Training in medicine has traditionally been based upon an apprenticeship model whereby the novice is taught by an 'expert' (usually within the clinical arena); ultimately becoming master craftsman him or herself Chur $\mathrm{H}$ et al. [5]. However, such a model has been significantly challenged by a number of factors including the European Working Time Directive and its impact on available training time, variability in trainee exposure and increased emphasis on patient safety Motola et al. [6]. Such concerns may in part be responsible for the exponential rise of simulation training within medical education over the past two decades.

Simulation-based medical education (SBME) enables trainees to learn within a safe, controlled environment without compromising patient safety [7-9]. In addition, SBME offers the opportunity for formative assessment and feedback. The basis of simulation is underpinned by the concepts of deliberate practice and mastery learning; the former refers to the identification and practice of specific components of a skill, which provides immediate feedback to promote improvement Ericcson [10]. Ericcson (2004) argues that deliberate practice is critical to the acquisition of motor skills and pivotal to the transition from competency to expertise. Indeed, Ericcson's research highlights that deliberate practice is a more powerful predictor of expert performance than is academic aptitude or experience. Deliberate practice is of particular importance when considering motor skills that are rarely performed (i.e. emergency surgical cricothyroidotomy) and thus offers little opportunity for practice within the clinical setting. The concept of mastery dates back to 1960s Motola et al. [6] and has its origins in engineering education.

In essence, mastery learning is competence-based education that aims to ensure all learning objectives are attained by all learners; eliminating variation in trainee outcomes as far as possible Wong \& Kang [11]. However, it is acknowledged that learners may take varying amounts of time to achieve mastery [12]. A number of authors have documented various positive translational outcomes of SBME including reduced length of hospital stay, fewer intensive care admissions as well as reduced health care costs Barsuk et al. [13]. For instance, a recent systematic review undertaken by Cook et al. [14] comparing mastery SBME with traditional training within healthcare reported that SBME had a large and statistically significant effect upon skill acquisition and a moderate effect upon patient outcomes.

\section{Curriculum}

A hybrid SBME program that incorporates an initial didactic lecture, skill stations and intermediate-fidelity simulation 
scenarios with the focus on the recognition and management of airway compromise, aimed specifically at junior surgical trainees working within ENT surgical departments is proposed. As a prerequisite, participants should be working within an ENT department and have completed both ALS and ATLS. Although, a number of airway management courses are already currently available, these appear not to include all the elements outlined above. Furthermore, the vast majority may be arguably too basic for the junior surgical trainee working within ENT surgery (i.e. ALS), or indeed too advanced; being aimed at anaesthetic or ENT specialty trainees. The course will not only aim to teach participants the technical skills required to manage patients with airway compromise, it will also address the non-technical elements through the use of simulation scenarios.

This will be performed in a three-step manner whereby participants can build open their knowledge by first providing the opportunity to learn or review underlying theoretical principles of airway management, followed by the practice of specific skills or procedures, before finally applying such knowledge and skill later within the simulation scenarios. Windsor [15] outlines a hierarchy of surgical skill acquisition beginning with basic or core skills, becoming more complex and automatic with the attainment of procedural and non-technical skills. Professor Windsor, a surgeon himself, emphasises that in traditional surgical training, the trainee is expected to master skills from all such domains simultaneously. He follows further that SBME enables trainees to learn appropriate skills at a time that is appropriate to their experience. This is somewhat in keeping with Bloom's Taxomony of Learning 1956 cited in Amer [16] that outlines three educational domains as cognitive (knowledge), psychomotor (skills) and affective (attitudes) and follows that educators and the learning activities they use should facilitate all levels of learning commencing with the most basic and building to a level which ultimately fosters high cognitive education [17].

\section{Skills stations}

The trainees will rotate through three skills stations in small groups. Each station will be led by one senior clinician and will be interactive to enable participants to discuss and clarify ideas and issues. Each station will provide the opportunity for 'hands on' practice in basic airway skills (simple adjuncts) and intubation, surgical airways (cricothyroidotomy and tracheostomy) and fibro-optic nasoendoscopy. Skills will be performed on cadaveric head and neck specimens [18-20].

\section{Intermediate-fidelity simulation}

Skill stations will be followed by a series of simulation scenarios using a Sim Man patient simulator; all with the theme of management of patients with rapidly deteriorating airway problems. The scenarios will be formulated from a combination of real life examples and learning needs assessments. Participants will undertake simulation scenarios individually, playing their true role as ENT surgical house officers and will be assisted by other participants and facilitators who will assume the role of nursing and anesthetic staff to increase the realism of the scenario. Realism is important in fostering the notion of suspension of belief whereby participants 'buy into' the scenario as a real life clinical situation [21-23]. Each scenario will last 8-10 minutes in duration and will be preceded by a concise briefing in the form of a referral or handover. The remaining participants will follow the progress of each scenario via a live video feed.

The simulation scenarios will not only provide an opportunity for participants to transfer and apply the knowledge and skills acquired from the previous activities it will also assess candidate ability to function as an effective team member. In modern medical practice, there is increasing emphasis being placed upon the impact of the clinical environment, wider team dynamics and human factors Marshall \& Flanagan [24] and it has been shown that effective team working is an essential component of care delivery and overall patient outcomes. In particular, communication, or more specifically, miscommunication was indicated as a root cause of almost $70 \%$ of significant events Joint Commission of Sentinel Events [25]. Despite this, undergraduate and early surgical education has traditionally failed to address the skills required to work effectively within teams; focusing primarily on knowledge and acquisition of technical skills Flanagan et al. [26].

\section{Debriefing and feedback}

Feedback is an integral aspect of learning within SBME. Van De Ridder et al. [27] define feedback as an activity that involves the giving of specific information around a trainee's observed performance given with the intent to improve their performance. Debriefing is a specific form of feedback employed in SBME and has been described as the single most important part of simulation training Rall et al. [28]. The importance of debriefing and feedback can perhaps be explained again by the work of Kolb's four-stage model of experiential learning (1984 cited in Motola et al. [6]) that reinforces that enhanced learning occurs when participants are given feedback to form the basis of a postreflective process where they are able to make sense of events through analysis and subsequently implement new ideas and theories to facilitate improvement (Figure 1).

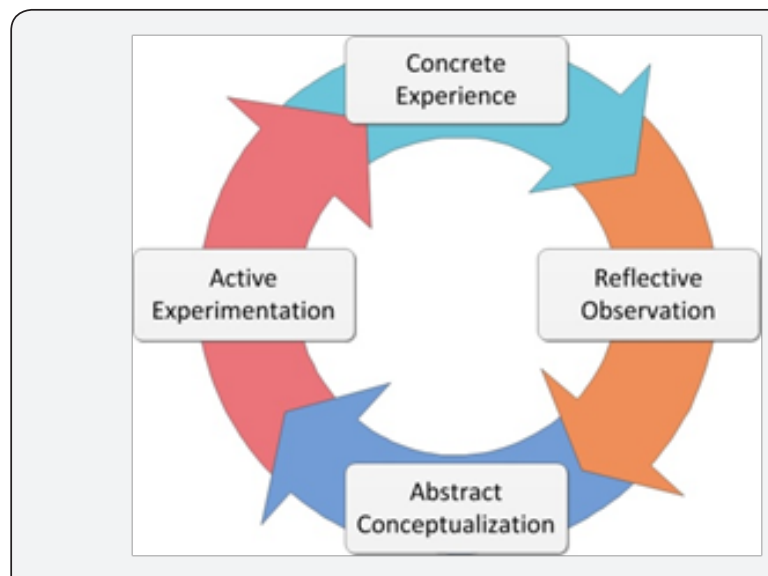

Figure 1: Kolb Cycle of Experiential Learning 
Savoldelli et al. [29] support this highlighting that isolated simulation encounters without feedback often fails to lead to trainee improvement, particularly in the domain of non-technical skills. It must however be borne in mind that feedback has the potential to be demoralising and counterproductive; having a negative impact upon learning if delivered ineffectively Wulf et al. [30]. Given the importance of debriefing, a significant amount of time will be allocated to undertaking this process (up to 40 minutes for each scenario) and will be undertake as a group activity facilitated by two instructors [31].

\section{Conclusion}

Although it is clear that simulation in health care can be effective, to date empirical evidence around aspects of development, instructional design as well as implementation of simulation programs is largely lacking. With specific reference to SBME in surgery, there is strong evidence that simulation is an effective educational activity for the acquisition of surgical and non-technical skills. More specifically, SBME is also proving to be important in airway management education and as such may be an invaluable adjunct to the current ENT specialty training curriculum. Within core surgical training where no formal curriculum exists around acute airway management however, simulation may offer the only opportunity for formal teaching before junior doctors working in ENT are faced with a real life patient with airway compromise.

\section{References}

1. Kovacs G, Law JA, Ross J, Tallon J, MacQuarrie K, et al. (2004) Acute airway management in the emergency department by nonanesthesiologists. Can J Anaesth 51(2): 174-180.

2. Wong E, Ngu Y (2008) The difficult airway in the emergency department. Int J Emerg Med 1(2): 107-111.

3. Awad Z, Pothier DD (2007) Management of surgical airway emergencies by junior ENT staff: a telephone survey. J Laryngol Otol 121(1): 57-60.

4. Intercollegiate Surgical Curriculum Programme (2013) Core surgical training. ISCP: London.

5. Chur HA, McLean S (2007) Supervisors' views about their trainees and supervision. Australas Psychiatry 15(4): 273-275.

6. Motola I, Devine LA, Chung HS, Sullivan JE, Issenberg SB (2013) Simulation in healthcare education: A best evidence practical guide. AMEE Guide No. 82. Med Teach 35(10): e1511-1530.

7. Rosen MA, Weaver SJ, Lazzara EH, Salas E, Wu T, et al. (2010) Tools for evaluating team performance in simulation-based training. J Emerg Trauma Shock 3(4): 353-359.

8. Issenberg SB, McGaghie WC, Petrusa ER, Lee Gordon D, Scalese RJ (2005) Features and uses of high-fidelity medical simulations that lead to effective learning: A BEME systematic review. Med Teach 27(1): 1028.

9. Gaba DM (2004) The future vision of simulation in health care. Qual Saf Health Care 13(suppl 1): i2-10.

10. Ericsson KA (2004) Deliberate practice and the acquisition and maintenance of expert performance in medicine and related domains. Acad Med 79(10 Suppl): S70-81.
11. Wong BS, Kang L (2012) Mastery learning in the context of university education. Journal of the NUS Teaching Academy 2(4): 206-22.

12. Guskey TR (2010) Lessons of mastery learning. Educational Leadership: Interventions That Work, 68(2): 52-57.

13. Barsuk JH, Cohen ER, McGaghie WC, Wayne DB (2010) Long-term retention of central venous catheter insertion skills after simulationbased mastery learning. Acad Med 85(10 Suppl): S9-12.

14. Cook DA, Hatala R, Brydges R, Zendejas B, Szostek JH, et al. (2011) Technology-enhanced simulation for health professions education: a systematic review and meta-analysis. JAMA 306(9): 978-988.

15. Windsor JA (2009) Role of simulation in surgical education and training. ANZ J Surg 79(3): 127-132.

16. Amer A (2006) Reflections on Bloom's Revised Taxonomy. Electronic Journal of Research in Educational Psychology 4(1): 213-230.

17. Biggs J (1996) Enhancing teaching through constructive alignment. High Educ 32(3): 347-364.

18. Donna MM (2010) Research and Evaluation in Education and Psychology. Integrating Diversity With Quantitative, Qualitative, and Mixed Methods ( $3^{\text {rd }}$ Edn) California, SAGE Publications Inc.

19. Prabhu A, Correa R, Wong (2001) What is the optimal training interval for cricotyroidectomy? Canadian Journal of Anaesthesiology 48: A59.

20. Wong DT, Prabhu AJ, Coloma M, Imasogie N, Chung FF (2003) What is the minimum training required for successful cricothyroidotomy?: a study in mannequins. Anesthesiology 98(2): 349-353.

21. Allinier G (2011) Developing High-Fidelity Health Care Simulation Scenarios: A Guide for Educators and Professionals. Simulation \& Gaming 42: 9-26.

22. Donnelly R (2009) Supporting teacher education through a combined model of philosophical, collaborative and experiential learning. Journal of the Scholarship of Teaching and Learning 9(1): 35- 63.

23. Wheelan SA, Burchill CN, Tilin F (2003) The link between teamwork and patients' outcomes in intensive care units. American Journal Critical Care 12(6): 527-534.

24. Marshall SD, Flanagan B (2010) Simulation-based education for building clinical teams. J Emerg Trauma Shock 3(4): 360-368.

25. Joint Commission of Sentinel Events (2011) Sentinel Event Data Root Causes by Event Type. Joint Commission of Sentinel Events.

26. Flanagan B, Nestel D, Joseph M (2004) Making patient safety the focus: Crisis resource management in the undergraduate curriculum. Med Educ 38(1): 56-66.

27. van de Ridder JM, Stokking KM, McGaghie WC, ten Cate OT (2008) What is feedback in clinical education? Med Educ 42(2): 189-197.

28. RallM, Manser T, Howard S (2000) Key elements of debriefing for simulator training. European Journal of Anaesthesiology, 17(8): 516517.

29. Savoldelli GL, Naik VN, Park J, Joo HS, Chow R, et al. (2006) Value of debriefing during simulated crisis management: Oral versus videoassisted oral feedback. Anaesthesiology 105(2): 279-285.

30. Wulf G, Chiviacowsky S, Lewthwaite R (2010) Normative feedback effects on the learning of a timing task. Res Q Exerc Sport 81(4): 425431.

31. Rudolph JW, Simon R, Raemer DB, Eppich WJ (2008) Debriefing as formative assessment: Closing performance gaps in medical education. Acad Emerg Med 15(11): 1010-1016. 
This work is licensed under Creative Commons Attribution 4.0 Licens

DOI: 10.19080/JHNSS.2017.01.555553

\section{Your next submission with Juniper Publishers will reach you the below assets}

- Quality Editorial service

- Swift Peer Review

- Reprints availability

- E-prints Service

- Manuscript Podcast for convenient understanding

- Global attainment for your research

- Manuscript accessibility in different formats

( Pdf, E-pub, Full Text, Audio)

- Unceasing customer service

Track the below URL for one-step submission https://juniperpublishers.com/online-submission.php 